\title{
HYDRODYNAMIC CHARACTERISTICS OF PULSED PACKED EXTRACTION COLUMNS
}

Milan N. Sovilj"', Momčilo Đ. Spasojević²

${ }^{1}$ University of Novi Sad, Faculty of Technology, Novi Sad, Serbia

2University of Novi Sad, Faculty of Technical Sciences, Novi Sad, Serbia

This work presents an overview of the research related to the determination of hydrodynamic characteristics of pulsed packed extraction columns using different liquid-liquid two-phase systems. The following hydrodynamic characteristics are examined: flooding velocity, mean drop diameter of the dispersed phase, the dispersed-phase holdup, and an axial dispersion coefficient. In this paper, the effects of operating parameters (pulsation velocity, superficial velocities of the phases) on the flooding point data taken from the literature are analyzed. The experimental data taken from the literature indicate that the maximum throughput of extraction devices decreases with an increase in pulsation velocity and the flow rate of the phases. By comparing these experimental data for liquid-liquid two-phase systems presented in the literature, it has been concluded that the overall flooding velocity decreases with increasing the flow rate ratio of the phases. It has been determined that the Sauter mean drop diameter is significantly dependent on pulsation velocity and interfacial tension, and that it is not a function of flow rates of the phases. The dispersed-phase holdup has been shown to increase with increasing the flow rate ratio, reaching its maximum value at the flooding point, when small drops are formed. It has been concluded that the dispersed-phase holdup increases with an increase in the flow rate ratio. The authors have presented and analyzed some of the empirical correlations taken from the literature for flooding velocity, mean drop diameter, dispersed-phase holdup, and axial dispersion coefficient as functions of operating parameters, packing characteristics, and physical properties of liquid-liquid systems.
(REVIEW PAPER)

UDC 532.5:66.061.35

Keywords: flooding velocity, Sauter mean drop diameter, dispersed-phase holdup, axial dispersion coefficient

\section{Introduction}

After distillation, a liquid-liquid extraction is the second most important separation operation in chemical and process industries. It is used in chemical and petrochemical industries, hydrometallurgy, biotechnology, nuclear technology, separation processes in food industry, a wastewater treatment and similar technologies [1, 2]. Significant implementation of the liquid-liquid extraction has recently been tied to processes in metallurgy, the uranium-based fuel treatment, the regeneration of spent combustible components in nuclear industry and the regeneration of copper from weak acid solutions [3]. Separation processes that include the liquid-liquid extraction are conducted in different types of column devices [4-6]. In some of these processes chemical complexes between the solute and solvent are formed, and this makes the knowledge of the hydrodynamics, mass transfer and kinetics of these processes a very important segment in the design of column extractors. The efficiency of column extractors primarily depends on the degree of turbulence within liquid-liquid systems and the size of the interfacial area, which is responsible for the intensity of mass transfer. One way of increasing the mass transfer velocity in column extractors is the introduction of pulsations into the two-phase system, as they intensify the mixing of fluids inside the device. The study of the hydrodynamic characteristics and phenomena of mass transfer in pulsed extractors has been the subject of extensive scientific research, primarily due to the complex behavior of liquid-liquid systems. It was established in the literature [7] that the operation of a pulsed packed extraction column (PPE column) was more efficient if it did not contain internal mechanical components, if liquid loss was reduced to the minimum and if the pulsator was isolated from the operating fluid. The PPE column is in fact an improved version of the standard column extractor, particularly if used in the separation of radioactive solutions, as its internal components are corrosion-free because the pulsator is located outside the device. The authors of the work [8] state that the advantage of the PPE column is that it does not contain moving mechanical parts, which obviates the need for servicing its operating components. This advantage contributes to its extensive use in chemical, oil, and other industries, as well as in biochemical technologies. Amani et al. [9] investigated the hydrodynamic behavior and mass transfer characteristics in a pilot plate packed bed extraction col-

\footnotetext{
*Author address: Milan N. Sovilj, University of Novi Sad, Faculty of Technology,

Bulevar cara Lazara 1, 21000 Novi Sad, Serbia

E-mail: miso@uns.ac.rs

The manuscript received: January,30, 2020.

Paper accepted: March, 04, 2020
} 
umn in the liquid propane-mercaptan-caustic system. The extraction column was filled with Pall ring structured packing. Mercaptan was extracted from the continuous phase to the dispersed phase, accompanied by a chemical reaction in the propane-mercaptan-caustic system. The pulsing was introduced into the column to enhance the mass transfer rate. As packing, PPE columns use metal rings, ceramic or stainless steel Raschig rings, Berel saddles, Pall rings, wire structured and other types of packing [10].

The aim of this work is to present the comparison of experimental results taken from the literature and relating to the hydrodynamic characteristics of PPE columns as a function of pulsation velocity, flow rate ratio of liquid phases, superficial velocities of the phases, interfacial tension and packing parameters. In these experimental results, the data presented were obtained using different liquid-liquid two-phase systems. The results were compared for hydrodynamic characteristics such as flooding velocity, mean drop diameter, dispersed-phase holdup and axial dispersion coefficient in relation to the operating parameters of the column extractor (pulsation velocity, continuous and dispersed phase superficial velocities, flow rate ratio, and interfacial tension).

The basics of the PPE column hydrodynamics

The main hydrodynamic characteristics of pilot plant PPE columns are flooding velocity, mean drop diameter of the dispersed phase, the dispersed-phase holdup, and an axial dispersion coefficient. Flooding velocity was typically calculated from empirical correlations presented in the literature and based on the concept of characteristic velocity $[11,12]$. These correlations take into account the data on pulsation velocity, physical properties of liquid-liquid systems and column packing characteristics. Experimental measurements of the dispersed-phase holdup in the column under flooding conditions were typically conducted in the steady state of the two-phase system and with sudden disruption of the flow of the phases (by closing the valve at each end of the column), thus allowing for the dispersed phase to coalesce in the interfacial area at the column top. After a certain point, the change in the interfacial area height, which represented the dispersed-phase height in the column, was measured. In all experiments, after reaching the steady column operation for given flow rates of the phases was reached, the dispersed-phase holdup was determined using the sampling method. Namely, during the operation of the column dispersion, the samples were rapidly taken from several positions (up to 7) along the column height by filling special cylinders (50 or $100 \mathrm{ml}$ ) with the dispersion. Once the dispersion was separated, i.e. the drops rose to the cylinder top, the dispersed-phase holdup was determined. It represented the ratio of the dispersed-phase volume to the volume of dispersion in the cylinder [13]. The flooding point was determined by measuring the difference in pressures at the column bottom and top, using an inverted U-tube. The mean drop diameter of the dispersedphase was estimated via a photographic technique where the drops were photographed using a digital camera and the appropriate software. The mean drop diameter was translated into absolute values by comparing the measured values with the packing opening values. The axial dispersion coefficient was determined using an aqueous tracer solution that was continuously introduced into the bottom of the column device under steady operating conditions. The axial dispersion coefficient was obtained indirectly, based on the measurement of the tracer concentration profile in the continuous phase along the column device.

A typical scheme of the PPE column with mass transfer is presented in Figure 1.

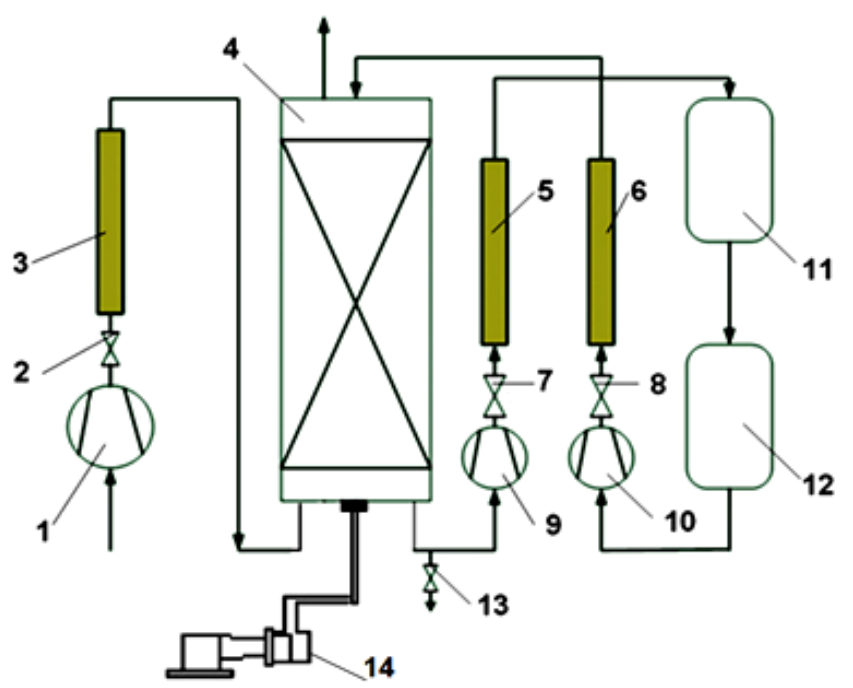

Figure 1. Schematic flow diagram of the pulsed packed extraction colum.

Legend: 1. Pump A. (Light phase in); 2, 7, 8, 13. Valves; 3, 5, 6. Rotameters; 4. Extraction column; 9. Drain pump, 10. Pump B. (Heavy phase in), 11, 12. Reservoirs of the heavy phase; 14. Pulsator pump.

\section{Flooding velocity}

The design of the countercurrent flow in all liquid-liquid extraction columns requires the determination of a suitable cross-section area for the liquid flow and the operating height of the column in order to achieve the desired mass transfer efficiency. Although the calculation of the cross-section area is considerably easier and more reliable than the estimation of the column device operating height, there are significant uncertainties, except when a pilot plant column is used as the basis for the design of the device [14]. If this calculation is viewed from the perspective of industrial implementation, the extraction column should achieve high separation efficiency and throughput. On the other hand, it is not possible to increase the flow rate of liquid phases indefinitely, as there is a limit to the amount of one phase that can be dispersed in the other. When this limit is reached (flooding point), the dispersedphase drops can no longer fall or rise against the flow of the continuous phase, which means that a stable device operation cannot be accomplished. The maximum volumetric capacity of the extractor, i.e. flooding throughput, is the first value to be determined in the design of a PPE 
column [15]. The column diameter is then typically calculated based on the knowledge of the column behavior under flooding conditions, provided the operating flow rates are a function of the maximum flooding capacity fraction. A significant step in designing liquid-liquid PPE columns is the determination of the packing height in the case of differential extractors. Finally, the design of extraction columns requires the knowledge of corresponding correlation equations or the values of the overall mass transfer coefficients.
In the work [16] it has been determined that 60 to $75 \%$ of the extractor height was used to compensate for a significant decrease in the mass transfer efficiency due to the presence of backmixing in the column. The study [17] established that works presented in the literature, involving the correct design of extraction columns are based on the diffusion or backflow model, with one parameter accounting for all deviations from the ideal behavior in plug flow. In the work [18], the equation for the overall flooding velocity in PPE columns [Eq. (1)] was presented, as shown in Table 1.

Table 1. Empirical equations for the flooding velocity

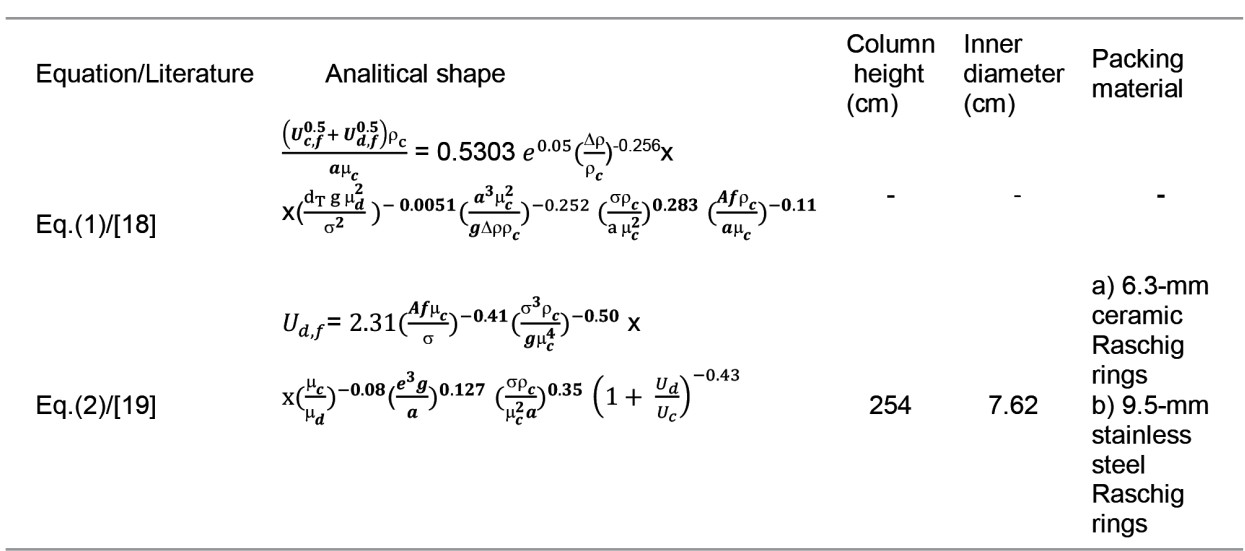

Equation (1) takes into account pulsation velocity $(A \cdot f)$, packing characteristics $(e)$ and physical properties of liquidliquid two-phase systems $(\rho c, \Delta \rho, \mu c, \mu d, \sigma)$. However, Equation (1) does not consider the impact of the flow rate ratio of the phases on the maximum column throughput although it is widely accepted that flooding velocity significantly varies with the change in the flow rate. Based on this it can be concluded that Equation1 does not provide very good agreement between calculated and experimental data.

One study [19] experimentally determined the behavior of four two-phase systems in a PPE column: kerosene-water, toluene-water, n-butyl acetate-water and butanol-water. The extraction column was $200 \mathrm{~cm}$ high and packed with $6.3 \mathrm{~mm}$ ceramic Raschig rings or $9.5 \mathrm{~mm}$ stainless steel Raschig rings. Its inner diameter was $7.62 \mathrm{~cm}$. The authors established that high values of pulsation velocity, which produced smaller-diameter drops, resulted in lower flooding velocities. A rise in pulsation velocity led to the intense shear stress in the column and affected drop breakage, i.e. the reduction in the drop diameter. The authors concluded that the number of drops in the operating part of the column increased due to a decrease in the slip velocity of the phases, which led to an increase in the dispersed-phase holdup in the operating part of the column. In this work [19], it was also shown that flooding velocity decreased with an increase in the dispersed to the continuous phase flow rate ratio. It was established that the dispersed-phase holdup increased with an increase in the flow rate ratio and that, as a consequence, the column became unstable at low dispersed-phase flow values. When the continuous phase was an aqueous solution of low viscos- ity, the rise in the dispersed-phase drop velocity was dependent on the drop diameter, as the drop diameter in the column extractor varied with the change in interfacial tension. For this reason, the dispersed-phase holdup in the column and the flooding point varied with the change in interfacial tension. After an increase in interfacial tension, the size of drops increased and the retention time in the operating part of the column was reduced. When the slip velocity of the phases in the column was increased, the dispersed-phase holdup decreased and the operation of the column device became much more stable. It was determined that low interfacial tension led to a lower allowed throughput than higher interfacial tension, as the column then contained smaller drops. The dispersed-phase holdup at the flooding point rose with the increased pulsation velocity, due to the formation of small drops. At the same time, the maximum dispersed-phase holdup in the column increased with increasing the flow rate ratio. On the other hand, the dispersed-phase holdup at the flooding point increased with the reduction in interfacial tension [19]. Due to the differences in void fractions of packing and the geometry of the phase contact area. Different column packings had different interactions with the dispersedphase drops. This means that the type of packing had a significant effect on the flooding point.

In work [19], a new equation [Eq. (2)] was developed for the dispersed-phase superficial velocity at the flooding point, as shown in Table 1.The average absolute relative deviation (AARD) between the calculated values for $U_{d, f}$ and the experimental data was $6.45 \%$, with the maximum absolute deviation of $22.7 \%$. 
When flooding is achieved, the dispersed phase accumulates at certain points in the interfacial area of the liquid-liquid system. Sometimes a phase inversion also occurs. Pulsed columns can be used as sieve-plate columns, packed columns or columns with discs and doughnuts. Most of the research relates to sieve-plate columns [20-22], while there is relatively little information in the literature on the performance of PPE columns. Therefore, in order to determine the efficient design procedures for PPE columns, it is necessary to develop the adequate empirical correlations for flooding velocity and the dispersed-phase holdup at flooding as a function of operating conditions in the column, packing geometry and physical properties of the liquid-liquid system.

In the work [23], it was established that pulsations introduced into a PPE column significantly impacted the hydrodynamics of the liquid-liquid system when stainless steel super mini rings (SMR) were used as packing. The comparison of the results obtained from three different packings (ceramic Raschig rings, stainless steel Raschig rings and SMR) showed that the SMR packing had the best characteristics as a function of the throughput and the mass transfer coefficient. The authors used a two-phase system of $30 \%$ tributyl phosphate (TBP) in kerosene-acetic acidwater. This work [23] recorded that the flooding velocity of the PPE column with the stainless steel Raschig ring packing had an approximately $30 \%$ higher value than that of the same column with ceramic Raschig rings. On the other hand, the dispersed-phase holdup at the flooding point of the column packed with stainless steel Raschig rings was lower than of the column with ceramic Raschig rings. Such behavior was conditioned by the fact that stainless steel Raschig rings have a larger void fraction of packing than columns with ceramic Raschig rings.

In the study [24], the authors determined the pressure drop in a two-phase system using three different liquidliquid systems - butyl acetate-water, toluene-water, and kerosene-water - with all the systems significantly different in terms of interfacial tension values with ceramic packs of the Raschig ring type of $0.63 \mathrm{~cm}$ in diameter. The flooding point was determined by indirect measurement of the dispersed-phase holdup through registering the difference in pressures along the extraction column height. The authors [24] established that the pressure drop along the height of the column $(\Delta p / H)$ significantly depended on the dispersed and continuous-phase flow rates and pulsation velocity. At the same time, it was found that an increased value of any of the operating parameters led to a higher pressure drop in the pulsed column. This work also presents empirical correlations for the pressure drop calculation in the gas-liquid system for PPE columns. The modified Khan and Varma correlation [25] was used for the calculation of the pressure drop in liquid-liquid PPE columns. Its application showed very good agreement between the calculated and experimental data $(\mathrm{AARD}=4.2 \%)$.

Based on the above-mentioned comments relating to the four investigated liquid-liquid two-phase systems [19], it was concluded that the overall flooding velocity
$\left(U_{f}\right)$ decreases with increasing the flow rate ratio $\left(U_{d} / U_{c}\right)$, and that flooding velocity has low values at high pulsation velocity $(A \cdot f)$ values. At the same time, the increased pulsation velocity results in an intense shear stress in the column which causes dispersed-phase drop breakage. It has also been shown that a decrease in dispersed to the continuous-phase flow rate ratio increases the number of drops in the operating part of the column, which, in turn, increases the dispersed-phase holdup. On the other hand, a pressure drop in the column is a function of the flow rate ratio of the phases. An increase in any of the operating characteristics in the PPE column leads to the increased pressure drop in it. Of the proposed empirical correlations for flooding velocity, only Equation 2 gives good agreement between calculated and experimental data.

\section{Mean drop diameter}

It is well known that the dispersed-phase mean drop diameter is a very important parameter in the examination and design of PPE columns. In modeling liquid-liquid extraction columns with the dispersed phase in the form of discrete drops, the surface-volume mean (Sauter) diameter $\left(d_{32}\right)$ is commonly used for the calculation of the interfacial area available for mass transfer, contact time, and mass transfer coefficients [26-29]. In order to develop effective procedures for the design of special types of extraction columns, the knowledge of the mean drop diameter values as a function of operating parameters, physical properties of the liquid-liquid system, and the direction of mass transfer in the two-phase system is of great importance [27]. These authors investigated the hydrodynamics and mass transfer in a rotating disc contactor using two two-phase systems: toluene-acetic acid-water and n-butanol-succinic acid-water.

One study [29] assessed the drop size distribution and the Sauter mean drop diameter in order to predict the size of the interfacial area for mass transfer. The authors used three different liquid-liquid systems and the hydrodynamics was examined in the absence of mass transfer in a pilot plant PPE column. The combined effect of pulsation velocity and interfacial tension achieved a great impact on the drop diameter distribution, while the impact of the flow rate of the phases was not significant. The extraction column height had an important role, especially in the lower, active part of the column, while the combined effect of the above-mentioned parameters decreased along the extraction column height. Using the well-known density function of the normal distribution, a procedure was developed for the calculation of the drop diameter distribution with the $A A R D=8.8 \%$. In the work (30), the effect of the packing type on drop size distribution in PPE columns was investigated by means of different columns and three packing types with three liquid systems including n-butyl acetatewater, toluene-water, and kerosene-water. The effect of operating variables in terms of pulse velocity and volumetric flow rates of the liquid phases was examined. Pulse velocity, interfacial tension and the packing shape were found to the main important factors for the drop size distribution. On the other hand, it was concluded that volumetric flow rates 
had no significant effect. Correlations are presented to predict drop distribution and mean drop size in PPE columns.

Work [31] examined the operating parameters of the PPE column. The column was packed with Raschig rings and its hydrodynamic characteristics were determined in a liquid-liquid 1-butanol-acetic acid-water two-phase system. The objective was to determine the concentrations of the solute (acetic acid) in the extract and raffinate and use the obtained data to calculate the column efficiency and the mass transfer coefficient. The well-known Murphreemodel and Kawase model [32] were used to calculate the efficiency of the extraction column. The analysis of these results showed a positive trend for both column efficiency and the mass transfer coefficient. The flow rate ratio was one of the most significant factors influencing the column efficiency, with the percentage increase of $33.57 \%$. In this work [31], an empirical correlation was developed for the calculation of the column efficiency that considers operating parameters in the two-phase system. The correlation showed good agreement with the results obtained using the Murphree model, with an average deviation of $7.35 \%$.

In the work [28], experimental studies in the PPE column were conducted for two two-phase systems: toluenewater and n-butyl acetate-water. In both systems acetone was used as the solute. It was established that the increase in the continuous-phase flow rate caused a slight increase in the mean drop diameter of the dispersed phase. The increase in the continuous-phase flow rate also resultedin the increased drop retention time in the column, due to a decrease in the slip velocity between the drops and the continuous phase. The increased drop retention time in the column created conditions for drop coalescence, which led to the formation of larger drops. A rise in pulsation velocity resulted in the formation of smaller-diameter drops. This was due to intense drop breakage that caused a fall in the value of the Sauter mean drop diameter. At very high pulsation velocity values, the fall in the values of the Sauter mean drop diameter was significant [28]. Drop coalescence was enhanced through a rise in pulsation velocity, which increased the probability of drop collision. High pulsation velocity thus increased the tendency for drop coalescence that exceeded the tendency for drop breakage. This led to the stabilization of the mean drop size. It was determined that the increase in the dispersed-phase flow rate $\left(Q_{d}\right)$ increased the mean drop diameter $\left(d_{32}\right)$ [28]. At the same time, the increase inthe mean drop diameter was attributed todrop coalescence caused by higher dispersedphase holdup.

The mean drop diameter in PPE columns is typically calculated using the semi-empirical correlation [Eq. (3)] proposed by the authors of the work [26], which is presented in Table 2.

Table 2. Empirical correlations for Sauter mean drop diameter

\begin{tabular}{|c|c|c|c|c|}
\hline Equation/Literature & Analitical shape & $\begin{array}{l}\text { Colum } \\
\text { height } \\
(\mathrm{cm})\end{array}$ & $\begin{array}{c}\text { Inner } \\
\text { diameter } \\
(\mathrm{cm})\end{array}$ & Packing material \\
\hline Eq. (3)/[26] & $\begin{array}{l}\frac{1}{d_{32}}-0.72\left(\frac{\Delta \rho g}{\sigma}\right)^{0.50}=6700\left(\frac{1-\varepsilon_{d}}{\varepsilon_{d}}\right) \times \\
\times\left(\frac{f A \rho_{c}}{\mu_{c} a_{p}}\right)\left(\frac{\mu_{c}^{2} a_{p}}{\sigma \rho_{c}}\right)^{0.50}\left(\frac{\sigma a_{p}^{2}}{\Delta \rho g}\right)^{0.23}\end{array}$ & (Om) & (оми & - \\
\hline Eq. $(4) /[28]$ & $d_{32}=\mathrm{c}_{1}\left(\frac{\sigma}{\Delta \rho g}\right)^{0.5}\left(\frac{\sigma}{A f \mu_{c}}\right)^{c_{2}}\left(1+\frac{U_{d}}{U_{c}}\right)^{c_{3}}$ & 180 & 7.62 & $\begin{array}{l}\text { 19-mm Raschig } \\
\text { ring }\end{array}$ \\
\hline
\end{tabular}

In the work [28], a correlation [Eq. (4)] was developed that can be used for predicting the Sauter mean drop diameter in PPE columns, as shown in Table 2.

Equation (4) takes into account the operating parameters and physical properties of liquid-liquid systems, with different values of the constants for different mass transfer directions. In the absence of mass transfer in the two-phase liquid-liquid system, the constants have the following values:

$\mathrm{c}_{1}=52.45 ; \mathrm{c}_{2}=0.30 ; \mathrm{c}_{3}=0.07$.

Mirzaie et al. [33] used the combination of the computational fluid dynamics (CFD) model and the droplet population balance model (DPBM) to simulate the drop size distribution and the range of the phase flow in a liquid-liquid pilot plant pulsed extraction column. The results related to the CFD-DPB model and the experimental results indicated that the dispersed-phase holdup increased with rising continuous and dispersed phase flow rates. At the same time, the increase in pulsation velocity resulted in increased dispersed-phase holdup, too. Due to a significant effect of drop breakage, the increased dispersed to continuous phase ratio caused a decrease in the Sauter mean drop diameter even at rising pulsation velocity.

The results presented so far indicate that a certain pulsation velocity to the interfacial tension ratio can achieve the greatest impact on the drop diameter distribution, while the impact of the flow rates of the phases is negligible. It is known that the increase in interfacial tension causes the increase in the drop diameter, with the drop retention time in the column decreasing. It has also been found that at increased pulsation velocity, the drops with smaller diameters are formed, due to the occurrence of intense drop breakage, i.e. a decrease in the value of the Sauter mean drop diameter. At the same time, pulsation velocity at high values causes a significant drop in the value of the Sauter mean drop diameter. Drop coalescence is enhanced by increasing pulsation velocity, thus increasing the likelihood for drop collision. Hence, high pulsation velocity increases the tendency 
for drop coalescence that exceeds the tendency for drop breakup and consequently results in the stabilization of the mean drop size. This part of the work also presents two empirical correlations for the calculation of the Sauter mean drop diameter based on the knowledge of operating characteristics and physical properties of liquid systems in extraction column devices. Correlation 4 provides very good agreement between calculated and experimental results for the Sauter mean drop diameter.

\section{Dispersed-phase holdup}

The concept of characteristic velocity $\left(U_{0}\right)$, introduced into the literature in the work [34], very useful for establishing the relation between the dispersed-phase holdup and superficial velocities of the dispersed and continuous phases:

$U_{s}=\frac{U_{d}}{e \varepsilon_{d}}+\frac{U_{c}}{e\left(1-\varepsilon_{d}\right)}=U_{0}\left(1-\varepsilon_{d}\right)$

The literature [35] shows that the dispersed-phase holdup is largely dependent on pulsation velocity and interfacial tension. The authors determined that the dispersed-phase holdup increased with increasing pulsation velocity and the flow rate ratio of the phases. It was also found that the results derived from characteristic velocity graphs could be used to describe variations in the dispersed-phase holdup with the fluid flow rate in the range of used pulsation velocity values. An empirical correlation was proposed for the dispersed-phase holdup as a function of operating variables, physical properties of liquid systems and packing characteristics. Good applicability of Equation (5) to the operation of PPE columns depends on the linearity of characteristic velocity. These results confirm the finding that this method can be used for PPE columns, since linear graphs are obtained for tested systems.

Experimental data for the dispersed-phase holdup can also be correlated as a function of physical properties of the system, operating characteristics, and packing parameters, [Eq.(6)], as proposed in work [19] and shown in Table 3. The calculated data and experimental values were shown to be in significant agreement: AARD $=5.45 \%$, with the maximum error of $22.37 \%$ [19].

Table 3. Equations for the dispersed-phase holdup

\begin{tabular}{|c|c|c|c|c|}
\hline Equation/Literature & Analitical shape & $\begin{array}{c}\text { Column } \\
\text { height } \\
\text { (cm) }\end{array}$ & $\begin{array}{c}\text { Inner } \\
\text { diameter } \\
\text { (cm) }\end{array}$ & Packing material \\
\hline Eq. (6)/[19] & $\begin{array}{l}\varepsilon_{d}=0.189 \mathrm{e}^{-0.486} \mathrm{x} \\
\mathrm{x}\left(\frac{A f \mu_{c}}{\sigma}\right)^{0.385} \mathrm{X} \\
\mathrm{x}\left(\frac{\sigma^{3} \rho_{c}}{g \mu_{c}^{4}}\right)^{-0.013}\left(\frac{\mu_{c}}{\mu_{d}}\right)^{-0.075}\left(\frac{\sigma \rho_{c}}{\mu_{c}^{2} a}\right)^{0.26} \mathrm{X} \\
\mathrm{x}\left(1+\frac{U_{d}}{U_{c}}\right)^{0.20}\end{array}$ & 254 & 7.62 & $\begin{array}{l}\text { a) } 6.3-\mathrm{mm} \\
\text { ceramic Raschig } \\
\text { rings } \\
\text { b) } 9.5 \text {-mm stainless } \\
\text { steel Raschig } \\
\text { rings }\end{array}$ \\
\hline E. $(7) /[35]$ & $\begin{array}{l}\varepsilon_{d}=0.615\left(\frac{A f \mu_{c}}{\sigma}\right)^{0.68}\left(\frac{\sigma^{3} \rho_{c}}{g \mu_{c}^{4}}\right)^{0.173} \mathrm{x} \\
\times\left(\frac{\mu_{c}}{\mu_{d}}\right)^{0.25}\left(\frac{e^{3} g}{a}\right)^{-0.186}\left(\frac{\sigma \rho_{c}}{\mu_{c}^{2} a}\right)^{-6.60} \times \\
\times\left(1+\frac{U_{d}}{U_{c}}\right)^{1.15}\end{array}$ & 254 & 7.62 & $\begin{array}{l}\text { a) } 6.3-\mathrm{mm} \\
\text { ceramic Raschig } \\
\text { rings } \\
\text { b) } 9.5-\mathrm{mm} \text { stainless } \\
\text { steel Raschig } \\
\text { rings }\end{array}$ \\
\hline
\end{tabular}

One explicit correlation for the dispersed-phase holdup is presented in work [35], Eq. (7). The dispersed-phase holdup value was correlated as a function of physical properties of the system, operating variables, and packing characteristics, as it can be seen in Table 3. The deviation of the experimental data for the dispersed-phase holdup from the calculated values determined according to Equation (7) in work [35] was satisfactory, with AARD = $13.96 \%$. The increased flow rate ratio of the phases $(Q d /$ Qc) in the column increased the number of the dispersedphase drops and, consequently, the dispersed-phase holdup. It was shown that the dispersed-phase holdup at flooding increased with the increase in pulsation velocity, which also led to the formation of smaller drops. As one of the important physical properties of liquid systems, inter- facial tension had a great impact on the dispersed-phase holdup, i.e. the dispersed-phase holdup varied considerably with changing interfacial tension. Specifically, the dispersed-phase holdup decreased with the increase in interfacial tension, since the drop size grew with increasing interfacial tension. This means that the retention time of drops in the operating part of the column was reduced, leading to a decrease in the dispersed-phase holdup in the column. Low interfacial tension resulted in a lower overall throughput than high interfacial tension, thus causing the formation of smaller drops. It was also established that the maximum column throughput decreased with increasing the pulsation velocity and the flow rate ratio of the phases, while it increased with increasing interfacial tension. 
In study [36], the dispersed-phase holdup and slip velocity were determined in a pilot plant extraction column for two different two-phase systems, in the presence and absence of mass transfer. The authors developed a new correlation for predicting the slip velocity of the phases as a function of operating parameters, physical properties of the liquid-liquid systems and packing characteristics. Very good agreement between the calculated and experimental data for the slip velocity of the phases was obtained.

In the above-mentioned part of the work, the authors analyzed the effects of the operating characteristics, geometric parameters and physical properties of the liquid-liquid systems on the dispersed-phase holdup. A rise in the number of drops in dispersion was caused by the increased ratio of the dispersed to continuous flow in the column, which led to the increase in the dispersedphase holdup in the operating part of the device. The dispersed-phase holdup at flooding grew with increasing the pulsation velocity, since small drops were formed at that point. At the same time, the maximum dispersedphase holdup increased with the increase in the ratio of liquid phases. On the other hand, the dispersed-phase holdup at flooding increased with a decrease in interfacial tension. The maximum throughput of the extraction column decreased with increasing the pulsation velocity and the flow rate ratio of the phases and increased with increasing interfacial tension. The study presented and analyzed two empirical correlations that provide the dependency of the dispersed-phase holdup on operating parameters, physical properties of the systems and packing geometry. The correlation (7) showed the best agreement between the calculated and experimental results for the dispersed-phase holdup.
Axial dispersion coefficient

The effect of backmixing in the continuous phase is a very important factor in calculating mass transfer in countercurrent liquid-liquid extraction columns. The calculations of mass transfer in column devices employ steady state and diffusion (dispersion) models. In mass transfer calculations, the continuous-phase axial dispersion coefficient $(E c)$ derived from the diffusion model [3739] was the most common characteristic value used as a measure of backmixing. In work [40], the experimental estimation of the overall volumetric mass transfer coefficient in the continuous phase also included the determination of the axial dispersion coefficient values in both phases $(E c, E d)$, using a PPE column and two threecomponent two-phase systems: toluene-acetone-water and n-butyl acetate-acetone-water. The experimental results were interpreted using the plug flow and diffusion models. This work [40] established that the increase in the dispersed-phase flow rate led to the increase in the axial dispersion coefficient in both phases. On the contrary, the increase in pulsation velocity caused a decrease in the axial dispersion coefficient in both phases. On the other hand, the minimum axial dispersion coefficient values in both phases were obtained at pulsation velocity in the range of 0.8 to $1.0 \mathrm{~cm} \mathrm{~s}-1$, followed by a slight increase in the axial dispersion coefficient. Two empirical equations [Eq. (8) and Eq. (9)] were also developed, related to the dependency of $E c$ and $E d$ on pulsation velocity, hydrodynamic characteristics, and physical properties of the liquid-liquid systems[40]. These equations are presented in Table 4.

Table 4. Empirical equations for the axial dispersion coefficient

\begin{tabular}{lcccc}
\hline Equation/Literature & \multicolumn{1}{c}{ Analitical shape } & $\begin{array}{c}\text { Column } \\
\text { height } \\
(\mathrm{cm})\end{array}$ & $\begin{array}{c}\text { Inner } \\
\text { Diamater } \\
(\mathrm{cm})\end{array}$ & $\begin{array}{c}\text { Packing } \\
\text { material }\end{array}$ \\
Eq. (8)/[40] & $\frac{E_{c}}{v_{c}}=1.48 \frac{R e^{0.6}}{\left(1-x_{d}\right)^{8.5}}\left(\frac{A f}{U_{s s}}\right)^{0.36}\left(\frac{U_{d}}{U_{c}}\right)^{0.47}$ & 150 & 7.62 & $\begin{array}{l}\text { Stainless steel } \\
\text { Raschig rings, } \\
10 m m \text { height, }\end{array}$ \\
Eq. (9)/[40] & $\frac{E_{d}}{v_{d}}=2.15 \frac{R e}{\left(1-x_{d}\right)^{6.8}}\left(\frac{A f}{U_{s s}}\right)^{0.62}\left(\frac{U_{d}}{U_{c}}\right)^{0.81}$ & 150 & 7.62 & $\begin{array}{l}\text { 9.5 mm outside } \\
\text { diameter }\end{array}$ \\
\hline
\end{tabular}

The valid range for the above equations was $8<R e<$ 125. The agreement between the experimental and calculated data for $E c$ end $E d$ obtained using Equations (8) and (9) was satisfactory, with the AARD of 16.81 and $16.19 \%$, respectively.

In work [41], the axial dispersion coefficient was estimated for the single-phase flow in a PPE column, using Raschig rings as packing and employing the imperfect pulse method for the determination of axial mixing. It was found that the axial dispersion coefficient decreased with increasing pulsation velocity. A three-parameter model was developed based on the well-known Taylor-Aris dispersion equation for flow through a tube [41]. This experimentally verified model represents the dependency of the axial dispersion coefficient on pulsation velocity, i.e. on superficial velocities of the phases. Study [42] presented the results of the axial dispersion coefficient estimation in a PPE column $\left(\mathrm{H}=404 \mathrm{~cm} ; d_{T}=5 \mathrm{~cm}\right)$ with structured packing $\left(d_{p}=5 \mathrm{~cm}\right)$, where the imperfect pulse method was also used for experimental measurements. The ratio $E / V$ of axial dispersion coefficient $(E)$ and kinematic viscosity $(v)$ of the liquid appeared to be a 
function of $R e$. The total fluid flow in the axial direction and pulsation velocity were characterised as a function of the Reynolds number. This function represents a fourparameter model, and it was experimentaly verified for different flow rates of the phases $\left(0-2 \mathrm{~cm} \mathrm{~s}^{-1}\right)$ and pulsation velocities $\left(0-4 \mathrm{~cm} \mathrm{~s}^{-1}\right)$. The employement of this model enabled the determination of pulsation conditions at the minimum value of the axial dispersion coefficient. Rafiei et al. [43] examined the characteristics of mass transfer in an L-shaped pulsed sieve-plate column using the axial dispersion model (ADM). The procedure employed two chemical systems: toluene-acetone-water and n-butyl acetate-acetone-water, with the mass transfer direction from the dispersed to the continuous phase. The effect of operating parameters (pulsation velocity and phase flow ratio) on the mass transfer performance was also determined. The mass transfer coefficient in the continuous phase was significantly larger than the coefficient in the dispersed phase. In this work [43], a new empirical correlation was developed and employed to determine the overall mass transfer coefficient and the axial dispersion coefficient. Yi et al. [44] investigated the impact of novel anti-corrosion ceramics (hybrid ceramics) and ceramic plates in the column on axial dispersion and mass transfer parameters in a standard two-phase system 30\% TBP in Shellsol 2046-acetic acid-water. The experimental results showed that hybrid ceramic packing decreased the axial dispersion coefficient by approximately $50 \%$, and increased the mass transfer coefficient by $50 \%$. The altered values of these coefficients had a positive impact on mass transfer parameters. Sovilj et al. [45] created a basis for the calculation of hydrodynamic characteristics in pilot plant pulsed packed extraction columns.

\section{Conclusion}

This work presents a comparative view of the effects of hydrodynamic characteristics of PPE columns such as flooding velocity, dispersed-phase holdup, mean drop diameter in the dispersed-phase and the axial dispersion coefficient on the efficiency and throughput of extraction columns. The experimental measurements taken from the literature have shown that the maximum throughput decreases with the increase in pulsation velocity and a flow rate of the phases, and increases with increased interfacial tension.

The experimental data taken from the literature and presented in this work for the mean drop diameter, flooding velocity, dispersed-phase holdup and axial dispersion coefficient in PPE columns can serve as a sound basis for the development of corresponding empirical correlations that can be used in designing these columns. For example, the knowledge of experimental values of the mean drop diameter of the dispersed phase in dispersion permits the calculation of the mass transfer coefficient, which is an important factor in calculations related to the design of column extractors. At the same time, the numerical data on the dispersed-phase holdup in the operating part of the column are useful in calculations of the required amount of the solvent used in the extraction process. Finally, the results presentedin this work represent on overview of the effects of the operating characteristics in PPE columns, parameters of the column device, and physical properties of liquid-liquid systems on the hydrodynamics of PPE columns. Mutual dependencies of these values can be utilized for the reliable calculation of mass transfer in these column devices.

\section{Nomenclature}

A - amplitude of pulsation, $m$

A.f $\quad$ - pulse velocity, $\mathrm{m} \mathrm{s}^{-1}$

AARD - average absolute relative deviation, AARD =

$$
(100 / N N) \sum_{i=1}^{N N}\left|\frac{\left.Y_{i}^{e k s p}-Y_{i}^{r a c}\right)}{Y_{i}^{e k s p}}\right|, \%
$$

a $\quad$ - specific interface area, $\mathrm{m}^{2} \mathrm{~m}^{-3}$

ap - packing surface area per unit volume of the column, $\mathrm{m}^{2} \mathrm{~m}^{-3}$

c1, c2, c3 - constants of empirical correlation (6)

d $\quad$ - average drop diameter, $m$

$d_{1} \quad$ - major axes of the drop, $m$

$d_{2} \quad-$ minor axes of the drop, $m$

de $\quad$ - equivalent drop diameter, $d_{e}=\left(\begin{array}{ll}d & d^{2}\end{array}\right)^{1 / 3}, \mathrm{~m}$

$d_{p} \quad$ - packing diameter, $m$

$d_{T} \quad$ - column diameter, $m$

$d_{32} \quad-$ volumetric/surface or the Sauter mean drop

$$
\text { diameter, } \mathrm{d}_{32}=\frac{\sum_{i=1}^{N} n_{i} d_{i}^{3}}{\sum_{i=1}^{N} n_{i} d_{i}^{2}}, \mathrm{~m}
$$

e

E

f

$g$

$\mathrm{H}$

$\mathrm{N}$

NN

- void fraction of packing

- axial dispersion coefficient, $\mathrm{m}^{2} \mathrm{~s}^{-1}$

- frequency of pulsation, $\mathrm{s}^{-1}$

- acceleration due to gravity, $\mathrm{m} \mathrm{s}^{-2}$

- column height, $m$

- number of experimental points in the Sauter mean drop diameter calculation

- number of points in AARD calculation

$\operatorname{Re} \quad$ - Reynolds number, $\operatorname{Re}=\frac{U_{s} d_{32} \rho_{c}}{\mu_{c}}$

$\checkmark \quad$ - phase flow, $\mathrm{m}^{3} \mathrm{~s}^{-1}$

$\mathrm{U} \quad$ - superficial velocity, $\mathrm{U}=4 \mathrm{~V} /\left(\mathrm{D}^{2} \pi\right), \mathrm{m} \mathrm{s}^{-1}$

$\mathrm{U}_{0} \quad$ - characteristic velocity, $\mathrm{U}_{0}=\left[\mathrm{U}_{\mathrm{d}} / \varepsilon_{\mathrm{d}}+\mathrm{U}_{\mathrm{c}} /(1\right.$

$\left.\left.-\varepsilon_{\mathrm{d}}\right)\right] /\left(1-\varepsilon_{\mathrm{d}}\right), \mathrm{m} \mathrm{s}^{-1}$

$U_{s} \quad$ - slip velocity, $\mathrm{m} \mathrm{s}^{-1}$

$U_{\text {ss }} \quad$ - slip velocity based on the superficial phase ve locities, $U_{s s}=\left(U_{d}+U_{c}\right), m^{-1}$

Yexp - experimental values of hydrodynamic charac teristics $\left(d_{32}, U_{d, f,} \varepsilon_{d}\right)$

Ycalc - calculated values of hydrodynamic characteris tics $\left(d_{32}, U_{d, f,} \mathcal{E}_{d}\right)$ 


\section{Greek letters}

$\Delta \rho \quad$ - density difference between phases, $\Delta \rho=\left(\rho_{c}-\right.$ pd), $\mathrm{kg} \mathrm{m}^{-3}$

$\Delta \mathrm{p} \quad$ - pressure drop during the column, $\mathrm{Pa}$

ed - dispersed-phase holdup

$\mu \quad$ - dynamic viscosity, Pa s

$\mathrm{V} \quad$ - kinematic viscosity, $\mathrm{m}^{2} \mathrm{~s}^{-1}$

$\rho \quad$ - density, $\mathrm{kg} \mathrm{m}^{-3}$

$\sigma \quad$ - interfacial tension, $\mathrm{N} \mathrm{m}^{-1}$

\section{Subscripts}

$\begin{array}{ll}\text { c } & \text { - continuous phase } \\ d & \text { - dispersed phase } \\ \text { f } & \text { - flooding point }\end{array}$

\section{References}

[1] A. J. F. Simons, in Handbook of Solvent Extraction, T. C. Lo, M. H. I. Baird, C. Hanson, Eds., John Wiley and Sons, New York, 1983, pp.343-353.

[2] H. R. C. Pratt, G. W. Stevens, in Science and Practice of Liquid-Liquid Extraction, J. D. Thornton, Ed., Oxford University Press, London, 1992, pp. 492-589.

[3] R. H. Perry, D. W. Green, Eds. in Perry`s Chemical Engineers' Handbook 7th Ed., McGraw-Hill Company, Inc, New York, 1997, pp. 15-22 $\div$ 15-46.

[4] S. Sharker, C. R. Philips, C. J. Mumford, Characterization of hydrodynamic parameters in rotating disc and Oldshue-Rushton columns: Hydrodynamic modelling, drop size, hold-up and flooding, Canadian Journal of Chemical Engineering, 63 (5) (1985) 701-709.

[5] L. M. Rincón-Rubio,A. Kumar,S.Hartland, Characterization of flooding in a Wirz extraction column, Canadian Journal of Chemical Engineering, 71 (1993) 844-851.

[6] M. N. Sovilj, B. G. Nikolovski, M. Đ. Spasojević, Hydrodynamics of a pilot plant spray extraction column, Acta Periodica Technologica, 49 (2018) 159-168.

[7] A. A. Hussain,Y. B. Liang, M. J. Slater, Characteristic velocity ofdrops in a liquid-liquid extraction pulsed sieve plate column, Chemical Engineering and Design,66 (1988) 541-554.

[8] M. Torab-Mostaedi, S. J. Safdari, M. A. Moosavian, M. G. Maragheh, Mass transfer coefficients in a Hanson mixer-settler extraction column,Brazilian Journal of Chemical Engineering, 25 (2008) 473-481.

[9] P. Amani, M. Amani,R. Hasanvandian, Investigation of hydrodynamic and mass transfer of mercaptan extraction in pulsed and non-pulsed packed columns, Korean Journal of Chemical Engineering, 34 (2017) 1456-1465.

[10] M. N. Sovilj, Difuzione operacije, Univerzitet u Novom Sadu, Tehnološki fakultet, Novi Sad, 2004, str. 172-192 (in Serbian).

[11] R. E.Treybal, Mass-Transfer Operations, 3rdEd.,McGrawHill International Editions, Chemical Engineering Series, Auckland, Tokyo, 1981, pp. 541-553.

[12] V. I. Kirou, L. L. Tavlarides, J. C. Bonnet, C. Tsouris, Flooding, holdup, and drop size measurements in a multistage column extractor, American Institute of Chemical Engineers Journal, 34 (2) (1988) 283-292.
[13] M. Torab-Mostaedi,J. Safdari, J.Prediction of mass transfer coefficients in a pulsed packed extraction column using effective diffusivity, Brazilian Journal of Chemical Engineering, 26 (4) (2009) 685-694.

[14] J. C. Godfrey, M. J. Slater, Slip velocity relationships for liquid-liquid extraction columns, Chemical Engineering Research and Design (Part A), 69 (1991)130-141.

[15] R. Berger, R. K. Walter, K., Flooding in pulsed sieve plate extractors, Chemical Engineering Science, 40 (1985) 2175-2184.

[16] Y. D. Wang, W. Y. Fei, J. H. Sun, Y. K. Wan, Hydrodynamics and mass transfer performance of a modified rotating disc contactor (MRDC), Chemical Engineering Research and Design (Part A), 80 (2002)392-400.

[17] H. J. Bart, C. Drumm, C., M.M. Attarakih, Process intensification with reactive extraction columns, Chemical Engineering and Processing, 47 (2008) 745754.

[18] G. V.Potnis, H. C. Bijawat, L. K. Doraiswamy,Upping column extraction efficiencyby pulse application-packed column, Industrial and Engineering Chemistry, 51 (5) (1959) 645-650.

[19] M. Asadollahzadeh,A.Haghighi-Asl, J. Safdari, M.TorabMostaedi, Flooding characteristics in pulsed packed extraction columns, Brazilian Journal of Chemical Engineering, 28 (4) (2011)639-648.

[20] A. B. Jahya, H. R. C Pratt, G. W. Stevens, Comparison of the performance of a pulsed disc and doughnut column with a pulsed sieve plate extraction column, Solvent Extraction and Ion Exchange,23, (2005), 307-317.

[21] R. L.Yadav,A.W.Patwardlan, Design aspects of pulsed sieve plate columns, Chemical Engineering Journal, 138 (2008) 389-415.

[22] A. Jahya, G. W. Stevens, H. R. C. Pratt, Pulsed disc-and-doughnut column performance, Solvent Extraction and Ion Exchange, 27 (2009) 63-82.

[23] J. Yu, W. Fei, Hydrodynamics and mass transfer in a pulsed packed column, Canadian Journal of Chemical Engineering, 78(2000)1040-1045.

[24] S. Khooshechin,J. Safdari, M. H. Mallah, Prediction of pressure dropin liquid-liquid pulsed packed extraction countercurrent columns, International Journal of Heat and Fluid Flow, 44 (2013) 684-691.

[25] A. Kumar,A., S. Hartland, Unified correlations for the prediction of drop size in liquid-liquid extraction columns, Industrial and Engineering Chemistry Research, 35 (1996) 2682-2695.

[26] N. M. Spaay, A. J. F. Simons, G. P. Ten Brink, G. P. Design and operation of a pulsed packed column for liquidliquid extraction, Proceedings of International Solvent Extraction Conference, The Hague (ISEC'71), Society of Chemical Industry, London, 1 (1971) 281-298.

[27] S. Soltanali, Y. Ziaie-Shirkolaee, Experimental correlation of mean drop size in rotating disc contactors (RDC), Journal of Chemical and Engineering of Japan, 41(9) (2008) 862-869.

[28] M. Torab-Mostaedi, J. Safdari, F. Torabi-Hokmabadi, Prediction of mean drop size in pulsed packed extraction columns, Iranian Journal of Chemical Engineering, 8 (4) (2011) 3-10.

[29] M. GholamSamani, A. Haghighi-Asl, J. Safdari, J., M. Torab-Mostaedi, Drop size distribution and mean drop size in a pulsed packed extraction column, Chemical Engineering Research and Design, 90 (12) (2012) 2148- 
2154.

[30] M. Golam Samani, J. Safdari, A. Haghighi-Asl, M. Torab-Mostaedi, Effect of structural parameters on drop size distribution in pulsed packed columns, Chemical Engineering and Technolgy, 37 (7) (2014) 1155-1162.

[31] A. P. D. Bernardes, L. M. N. Gois, Evaluation of efficiency and mass transfer in pulsed packed extraction column, Research, Society and Development, 9 (2) (2020)1-28.

[32] Y. Kawase,(1990). Dispersed-phase holdup and mass transfer in a rotating disc contactor with perforated skirts, Journal of Chemical Technology and BioTechnology, 48 (1990) 247-260.

[33] M. Mirzaie, A. Sarrafi, H. Hashemi Pour, A. Baghaie, M. Molaeinasab, Experimental investigation and CFD modeling of hydrodynamic parameters in a pulsed packed column, Solvent Extraction and Ion Exchange, 34 (7) (2016) 663-660.

[34] R. Gayler, V. W. Roberts, H. R. C. Pratt, Liquid-liquid extraction: A further study of holdup in packed column, Transactions of the Institution of Chemical Engineers, 31 (1953) 57-68.

[35] M. Asadollahzadeh, J. Safdari, A. Haghighi-Asl, M.TorabMostaedi, Dispersion phase hold-up and characteristic velocity in a pulsed packed extraction column, Chemical Industry and Chemical Engineering Quarterly, 18 (2) (2012)255-262.

[36] F. Torabi-Hokmabadi, H. Bahmanyar, M. Amanabadi, J. Safdari, Dispersed phase holdup and slip velocity of phases in a pulsed packed column with and without mass transfer, Canadian Journal of Chemical Engineering, 87 (2009) 855-861.

[37] T. Miyauchi,T. Vermeulen, Longitudinal dispersion in two-phase continuous-flow operations, Industrial and Engineering Chemistry Fundamentals, 2 (2) (1963) 113126.

[38] M. Sovilj, Hold-up and backmixing in liquid-liquid spray column, Proceedings of the International Solvent Extraction Conference-ISEC'88, July 18-24, Moscow, USSR, 2 (1988) 274-276.

[39] M. Sovilj, Axial Dispersion in a three-phase gas-agitated spray extraction column, Collection of Czechoslovak Chemical Communications, 63 (1998) 283-292.

[40] A. Safari, J. Safdari, H. Abolghasemi, M. Forughi, M. Moghaddam, Axial mixing and mass transfer transfer investigation in a pulsed packed liquid-liquid extraction column using plug flow and axial dispersion models, Chemical Engineering Research and Design, 90 (2012) 193-200.

[41] J. C. Göebel, K. Booij, J. M. H. Fortuin, Axial dispersion in single-phase flow in pulsed packed columns. Chemical Engineering Science, 41 (12) (1986) 3197-3203.

[42] A. N. S. Mak, C. A. J. Koning, P. J. Hamersma, J. M. H. Fortuin, Axial dispersion in single-phase flow in a pulsed packed column containing structured packing, Chemical Engineering Science, 46 (3) (1991) 819-826.

[43] V. Rafiei, J. Safradri, S. Moradi, P. Amani, M. H. Mallah, Investigationof mass transfer performance in an L-shaped pulsed sieve plate extraction columnusing axial dispersion model, Chemical Engineering Research and Design, 128 (2017) 130-145.

[44] H. Yi, Y. Wang, K. H.Smith, W. Fei, Axial dispersion and mass transfer of a pulsed solvent extraction column with novel ceramic internals, Industrial Engineering and
Chemistry Research,56 (11)(2017), 3049-3058.

[45] M. N. Sovilj, M. Đ. Spasojević, B. G. Nikolovski, Hydrodynamics of pilot plant pulsed packed extraction columns, Proceedings of $32^{\text {nd }}$ International Congress on Processing Industry' 19, 30-31.05. 2019., 111-120, Beograd, Serbia. 


\section{Izvod \\ HIDRODINAMIČKE KARAKTERISTIKE PULZACIONIH EKSTRAKCIONIH KOLONA SA PUNJENJEM}

Milan N. Sovilj ${ }^{1}$, Momčilo Đ. Spasojević

1 Univerzitet u Novom Sadu, Tehnološki fakultet, Novi Sad, Srbija

2Univerzitet u Novom Sadu, Fakultet tehničkih nauka, Novi Sad, Srbija

U ovom radu je dat pregled istraživanja, na bazi eksperimentalnih podataka iz literature, koja se odnose na određivanje hidrodinamičkih karakteristika pulzacionih ekstrakcionih kolona sa punjenjem u slučaju korišćenja različitih dvofaznih sistema tečno-tečno. Kao hidrodinamičke karakteristike korišćeni su: brzina plavljenja, srednji prečnik kapi dispergovane faze, sadržaj dispergovane faze, kao i koeficijent podužne difuzije. Analiziran je uticaj radnih parametara na tačku plavljenja u ekstrakcionoj koloni. Eksperimentalni rezultati su ukazali na to da maksimalni kapacitet ekstrakcionog uređaja opada sa porastom brzine pulzacije i protoka faza. Utvrđeno je eksperimentalno da ukupna brzina plavljenja opada pri povećanju odnosa protoka faza, kao i da ona ima male vrednosti kada su korišćene velike vrednosti brzine pulzacije. Potvrđeno je da Sauterov srednji prečnik kapi značajno zavisi od brzine pulzacije i međufaznog napona ali nije funkcija protoka faza. Pokazano je da sadržaj dispergovane faze u dispeziji raste sa povećanjem odnosa protoka faza, dok on u tački plavljenja dostiže svoju maksimalnu vrednost, pošto tada dolazi do formiranja sitnih kapi. Prikazane su i analizirane neke od empirijskih korelacija iz literature, koje se odnose na brzinu plavljenja, Sauterov srednji prečnik kapi, sadržaj dispergovane faze i koeficijent podužne difuzije kao funkcije radnih parametara, karakteristika punjenja i fizičkih osobina sistema tečno-tečno.
(PREGLEDNI RAD)

UDK 532.5:66.061.35

Ključne reči: brzina plavljenja, Sauterov srednji prečnik kapi, sadržaj dispergovane faze, koeficijent podužne difuzije 